\title{
Terminating and exhaustive search in lexical access
}

\author{
KENNETH I. FORSTER and ELIZABETH S. BEDNALL \\ Monash University, Clayton, Victoria, Australia 3168
}

\begin{abstract}
Two experiments which test predictions derived from the assumption that lexical access involves a search process are reported. In the first experiment, test items must be classified as ambiguous or unambiguous, and'in the second experiment, they are classified according to their syntactic properties. In both experiments, it is shown that when the target of the search is a nonexistent entry, an exhaustive search is involved, even though the test items are words. Further, in these conditions, frequency of occurrence is no longer related to decision time, as it is in lexical decision experiments. It is concluded that the search model adequately explains the procedure whereby the most common meaning of a homograph is accessed, but that the less common meaning is accessed in some completely different manrier.
\end{abstract}

In several recent papers, the suggestion has been made that recovery of information from lexical memory during reading requires an extensive search process (Rubenstein, Garfield, \& Millikan, 1970; Rubenstein, Lewis, \& Rubenstein, 1971; Stanners \& Forbach, 1973). Information about words is assumed to be stored in a set of files, or lexical entries, and when information about a given word is required, a search through a subset of these lexical entries is initiated, with the search being terminated when the correct entry is located.

The evidence for a search process derives from two findings. First, in lexical decision tasks (word-nonword classification), orthographically legal nonwords (e.g., thamon) take longer to classify than words (Rubenstein et al., 1970; Stanners \& Forbach, 1973; Snodgrass \& Jarvella, 1972; Forster \& Chambers, 1973). Second, high frequency words are classified faster than low frequency words (Rubenstein et al., 1971; Forster \& Chambers, 1973). The first finding is explained by the fact that nonwords require an exhaustive search of the subset of the lexicon in order to determine that no entry is present, which must take longer than a self-terminating search for a word. The second finding is explained on the assumption that the most efficient organization of the lexicon would place the most frequently accessed words near the beginning of the list of entries to be searched.

Since these findings alone are scarcely sufficient to establish that lexical access requires serial examination of a range of lexical entries, it is important to discover whether there are additional phenomena that can be predicted from the search model. The present paper focuses on the expected outcomes when an exhaustive search is required for words, rather than nonwords.

This situation can be arranged by requiring subjects to decide whether a given orthographic array is associated with more than one meaning or not, i.e., whether it is an ambiguous word. This task will be referred to as

This research was supported in part by a grant from the Australian Research Grant Committee to the first author. Requests for reprints should be addressed to $K$. I. Forster, Department of Psychology, Monash University, Clayton. Victoria, Australia 3168. an ambiguity decision task. According to the search model, the method of reaching a decision would be to initiate a search, counting the number of lexical entries that are encountered with the required orthographic properties. When the count reaches two, the search can be discontinued, and the "Yes" response executed. However, so long as the count remains less than two, the search must be continued. Thus, for both unambiguous words and nonwords, an exhaustive search will be required.

On this analysis, there are three predictions that can be made. First, there is no reason to expect unambiguous words to be classified any faster than nonwords (in contrast to the normal result for a lexical decision task). Indeed, unambiguous words may well take longer than nonwords, since the search is likely to be interrupted in the former case when the first lexical entry is located. Second, there is no longer any basis for expecting high frequency unambiguous words to be classified any faster than low frequency unambiguous words, since in both cases the search does not terminate when the first entry is located. Third, since a terminating search will be involved for ambiguous words, decision times should be fastest in this condition. In this case, frequency should be a relevant variable, although it should only be the frequency of the less common meaning that is correlated with decision time.

This application of the search model is summarized in Figure 1. The two meanings of a homograph are assumed to be represented in two distinct entries, $L_{1}$ and $L_{2}$, the relative frequencies of occurrence of these meanings being $f_{1}$ and $f_{2}$, respectively, where $f_{1}>f_{2}$. The experiment to be reported employs four types of items: equiprobable unsystematic homographs (words with two quite unrelated meanings, where $f_{1}$ is approximately equal to $f_{2}$ ), unequiprobable unsystematic homographs (where $f_{1}$ and $f_{2}$ are not equal), unambiguous words, and orthographically legal nonwords. The relative positioning of the various entries within the search set reflects the fact that total frequency of occurrence has been equated across the three types of words. In Figure 1, decision time is indicated by the 

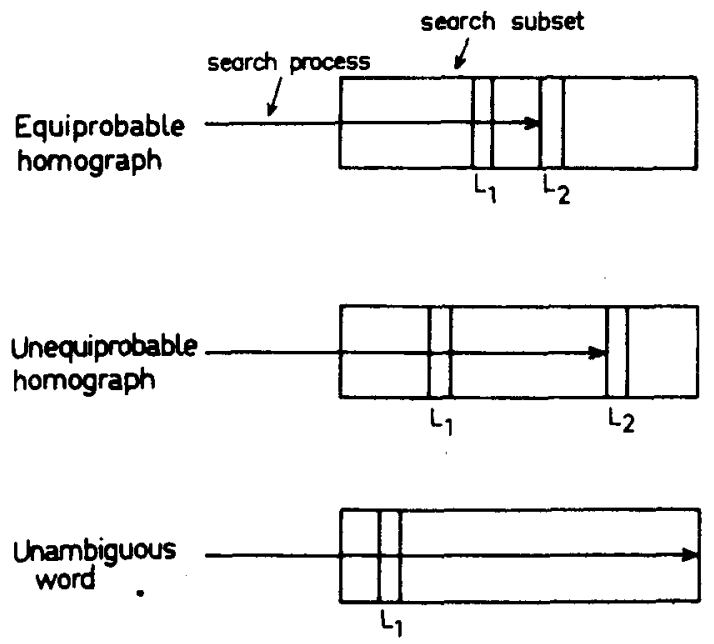

Nonword

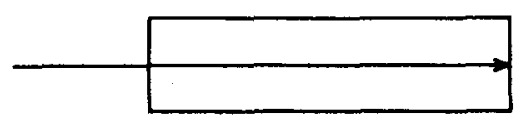

Figure 1. Hypothetical search model for the ambiguity decision task, where $L_{1}$ and $L_{2}$ are lexical entries.

length of the line representing the search process. It can be seen immediately that a corollary of the model outlined above is that ambiguity decision times should be shorter for equiprobable homographs than for unequiprobable homographs, since $f_{2}$ is higher in the former case than the latter (assuming that overall frequency has been held constant).

Of course, these predictions all depend on the assumption that the meanings of a homograph are stored in quite separate entries. When these meanings are quite unrelated semantically (e.g., CHEST), this does not seem unreasonable (Rubenstein et al., 1971). However, if this assumption is false, and all meanings of a word are stored within a single entry, then an exhaustive search would be unneccesary for unambiguous words, since an examination of the contents of $L_{1}$ will suffice to establish that the word is not ambiguous. In this case, the pattern of results obtained in an ambiguity decision task should parallel those for the lexical decision task.

These hypotheses are tested in Experiment I, which contrasts preformance on the ambiguity task and the lexical decision task for the same set of items. Experiment II takes up some of the issues raised in the first experiment, and also tests the same predictions using an entirely different kind of task.

\section{EXPERIMENT I}

The items used in this experiment consisted of both equiprobable and unequiprobable unsystematic homographs, unambiguous words and orthographically legal nonwords. The words were subdivided into high and low frequency groups according to total frequency of occurrence (Kucera \& Francis, 1967), while the frequencies of the separate meanings of each of the homographs were estimated by a rating method. Two separate groups of subjects were used, the first group classifying each item as ambiguous or unambiguous, the second group classifying the same set of items as words or nonwords.

\section{Method}

Selection of items. A group of 50 introductory students rated the frequencies of each of the meanings of a set of unsystematic homographs on a 10-point scale. Also included were a set of unambiguous words of known frequency to check the accuracy of the ratings. A further group of 50 students was asked which meaning of each of the homographs they first thought of. From this pool, 20 homographs were selected which most closely approximated the ideal of equiprobability (both meanings having equal rated frequency, and equally often thought of first), subject to the constraint that half the items had a relatively high total frequency of occurrence (above 20 on the KuceraFrancis count), and half had a low frequency (below 15). A further 20 homographs were chosen which matched the equiprobable set for total frequency of occurrence, and which were as unequiprobable as possible (a large difference in the rated frequencies of the two meanings, and one meaning thought of first more often than another). After selecting these groups, 20 unambiguous words were chosen which matched the homographs in frequency of occurrence. Also included were a set of 20 orthographically legal nonwords, the only constraint being that the distribution of item lengths across all four conditions should be as similar as possible. The complete set of items is given in the appendix.

Procedure. The items were typed in lower-case letters, and were filmed on 16-mm movie film. This film was presented with a variable speed motion projector. The items were arranged in a semirandom order so that practice effects were equally distributed over all conditions. Each item was displayed for $500 \mathrm{msec}$, and the interval between the presentation of each item and the subject's response was measured to the nearest millisecond.

Subjects in Group I were asked to press one key labeled "two or more" if the item had more than one meaning, or a key labeled "one or less" if the item was an unambiguous word or a nonword. Half the subjects held the "two or more" key in the preferred hand, half in the nonpreferred hand.

Subjects in Group II were shown the same film, and were asked to press a key labeled "Yes" if the item was a word, or a key labeled "No" if it was not, with a similar counterbalancing of the preferred hand.

Subjects. The subjects for the experiment were 30 undergraduate psychology students who were paid for their participation. None had previously been used in the pretesting of the experimental materials. There were 20 students in Group I and 10 in Group II.

\section{Results}

In order to minimize the effects of trials on which very long latencies were produced, cutoff points were established two standard deviation units above and below the mean reaction time for each individual subject, and any values exceeding these limits were set equal to the appropriate cutoff value. Using these adjusted latencies, means were determined for each subject in each condition (excluding trials on which the wrong response was made), and the means over subjects for each condition are given in Table 1 for the ambi. guity decision task (Group I), together with the percentage error rates. 
The predictions derived from the search model were tested using a conservative estimate of the quasi-F ratio required to establish generality over both the random effects of subjects and items (Clark, 1973).

Ambiguity decision times. The major predictions concern performance on the unambiguous words. First, it can be seen that, as predicted, unambiguous words are definitely not classified faster than nonwords (as they are in lexical decision experiments); in fact, nonwords are classified much faster than unambiguous words $\left[\mathrm{min} \mathrm{F}^{\prime}(1 / 35)=34.28, \mathrm{p}<.001\right]$. Somewhat unexpectedly, nonwords were also classified faster than the homographs, $\left[\min \mathrm{F}^{\prime}(1 / 74)=8.78, \mathrm{p}<.01\right]$. Second, it can be seen in Table 1 that the effect of frequency on the unambiguous words was only $5 \mathrm{msec}$, which proved not to be a significant effect $\left[\mathrm{min} \mathrm{F}^{\prime}\right.$ $(1 / 23)<1]$.

The results for the homographs, however, were not entirely consistent with the predictions. The first prediction, namely, that homographs would be classified faster than unambiguous words, was clearly confirmed, the effect of ambiguity in Table 1 being significant, $\left[\min F^{\prime}(2 / 60)=6.60, p<.01\right]$. The second prediction was that equiprobable homographs would be classified faster than unequiprobable homographs. This prediction was clearly disconfirmed, since if anything equiprobable homographs take longer to classify, although this was not a significant effect, $\left[\min \mathrm{F}^{\prime}(1 / 57)<1\right]$. The third prediction was that rated estimates of $\mathrm{f}_{2}$ would correlate negatively with classification times (a low rating corresponded to a low frequency). Over both types of homographs, the obtained correlation was in the expected direction, but was not significant, $[\mathrm{r}(38)=-0.16$, $\mathrm{p}>.05]$. It might be suggested that this result may be due to possible unreliability of the ratings. This possibility can be examined in the following way. It will be recalled that rated frequencies were also collected for a set of unambiguous words (these were not the same as the words used in this experiment). If ratings of frequen

Table 1

Mean Reaction Time (Milliseconds) and Percentage Error Rate as a Function of Item Type and Kucera-Francis Frequency for the Ambiguity Decision Task: Experiment I

\begin{tabular}{|c|c|c|c|c|c|c|}
\hline & \multicolumn{3}{|c|}{$\begin{array}{l}\text { High Frequency } \\
\text { (20 and Above) }\end{array}$} & \multicolumn{3}{|c|}{$\begin{array}{l}\text { Low Frequency } \\
\text { (Below 15) }\end{array}$} \\
\hline & $\mathrm{RT}$ & SE & $\begin{array}{c}\% \\
\text { Error }\end{array}$ & RT & SE & $\begin{array}{c}\% \\
\text { Error }\end{array}$ \\
\hline $\begin{array}{l}\text { Equiprobable } \\
\text { Homographs }\end{array}$ & 939 & 61 & 10 & 1001 & 65 & 16 \\
\hline $\begin{array}{l}\text { Unequiprobable } \\
\text { Homographs }\end{array}$ & 941 & 79 & 11 & 964 & 61 & 16 \\
\hline $\begin{array}{l}\text { Unambiguous } \\
\text { Words }\end{array}$ & 1091 & 87 & 11 & 1096 & 83 & 17 \\
\hline $\begin{array}{l}\text { Legal } \\
\text { Nonwords }\end{array}$ & 740 & 41 & 1 & & & \\
\hline
\end{tabular}

Note. The SE estimates are based on between-subject variation only.
Table 2

Mean Lexical Decision Times (Milliseconds) and Percentage Error Rates as a Function of Item Type and Kucera-Francis Frequency: Experiment I

\begin{tabular}{|c|c|c|c|c|c|c|}
\hline & \multicolumn{3}{|c|}{$\begin{array}{l}\text { High Frequency } \\
\text { (20 and Above) }\end{array}$} & \multicolumn{3}{|c|}{$\begin{array}{c}\text { Low Frequency } \\
\text { (Below 15) }\end{array}$} \\
\hline & RT & SE & $\begin{array}{c}\% \\
\text { Error }\end{array}$ & $\mathrm{RT}$ & SE & $\begin{array}{c}\% \\
\text { Error }\end{array}$ \\
\hline $\begin{array}{l}\text { Equiprobable } \\
\text { Homographs }\end{array}$ & 530 & 25 & 2 & 560 & 23 & 3 \\
\hline $\begin{array}{l}\text { Unequiprobable } \\
\text { Homographs }\end{array}$ & 521 & 22 & 1 & 562 & 23 & 3 \\
\hline $\begin{array}{l}\text { Unambiguous } \\
\text { Words }\end{array}$ & 541 & 26 & 1 & 587 & 26 & 9 \\
\hline $\begin{array}{l}\text { Legal } \\
\text { Nonwords }\end{array}$ & 683 & 30 & 13 & & & \\
\hline
\end{tabular}

Note. The SE estimates are based on between-subject variation only.

cy were unreliable, then there should be a low correlation with actual frequency. However, this was not the case, since rated frequency correlated well with KuceraFrancis frequency $[r(108)=0.64, p<.001]$. Further, in the original pretesting of the homographs, subjects were asked which meaning of the homograph they thought of first. It seems reasonable to suppose that the number of subjects reporting $\mathrm{L}_{2}$ (the less likely meaning) should be correlated with the rated estimates of $f_{2}$. This was the case $[r(38)=0.42, p<.01]$, although the correlation is far from perfect.

Thus the failure of $f_{2}$ to predict ambiguity decision time cannot be attributed simply to unreliability. Curiously enough, a post hoc test showed that in fact $f_{1}$ was correlated with decision time $[\mathrm{r}(38)=-0.32$, $p<.05]$.

Lexical decision times. Table 2 presents the mean lexical decision time for Group II, who were given the same items as Group I, but were required only to decide whether the item was a word or not.

Analysis of the data for the words in a 3 by 2 design with the main effects being ambiguity and frequency (high vs. low Kucera-Francis frequency) produced a significant effect of frequency, $\left[\min \mathrm{F}^{\prime}(2 / 75)=10.40\right.$, $\mathrm{p}<.011$. There was no significant effect of ambiguity $\left[\min \mathrm{F}^{\prime}(2 / 60)=0.82, \mathrm{p}>.05\right]$, nor was there a significant interaction between frequency and ambiguity [min $F^{\prime}(2 / 65)=0.12, p>05$ ] . Comparison of words with legal nonwords showed that, in contrast to the data in Table 1, legal nonwords took longer to classify than words $\left[\operatorname{min~} \mathrm{F}^{\prime}(1 / 44)=20.79, \mathrm{p}<.001\right]$.

\section{DISCUSSION}

The adequacy of the search model in accounting for the results is best illustrated by a detailed comparison of the results shown in Tables 1 and 2. It should be kept in mind that according to the search model, ambiguity decision requires the subject to detect the presence of 
both $\mathrm{L}_{1}$ and $\mathrm{L}_{2}$, whereas lexical decision requires only the detection of $\mathrm{L}_{1}$.

The most important respects in which Table 2 differs from Table 1 are as follows. (1) Unambiguous words take longer than homographs in the ambiguity decision task, but not in the lexical decision task. This follows from the assumption that unambiguous words require an exhaustive search of the subset in the ambiguity decision task, whereas homographs do not, while in the lexical decision task, the search terminates for both types of words when $L_{1}$ is accessed. (2) Kucera-Francis frequency exerts a significant effect on lexical decision times for unambiguous words, but not on ambiguity decision times; in particular, the frequency effect for unambiguous words is much greater for lexical decisions (46 msec) than for ambiguity decisions $(5 \mathrm{msec})$. This latter point is support for the view that an exhaustive search is necessary for unambiguous words in ambiguity decision, but not for lexical decision. (3) Legal nonwords take longer than unambiguous words for lexical decisions (as reported by numerous investigators), but for ambiguity decisions, nonwords are much faster than unambiguous words. This reversal is a product of two separate effects. In the lexical decision task, the difference between words and nonwords stems from the difference between a terminating and an exhaustive search. This difference disappears in the ambiguity decision task, since an exhaustive search is involved in both cases. However, a second effect is introduced in the ambiguity task, since the search for the nonexistent $\mathrm{L}_{2}$ in the case of an unambiguous word is interrupted when $L_{1}$ is encountered. Evidently, this interruption is fairly costly, requiring approximately $350 \mathrm{msec}$. This may be because there is a certain amount of cross-checking to be done when a match is discovered between the letters presented and the orthographic specifications laid down in the lexical entry, or it may simply be due to the fact that it takes considerable time to restart the search. Further evidence of the cost of this interruption is provided by the fact that legal nonwords were also faster than homographs, even though the latter items did not require an exhaustive search. (4) For words, ambiguity decisions are much slower $(1019 \mathrm{msec})$ than lexical decisions (551 msec), reflecting the extra search time and interruption time that ambiguity decision involves. But for nonwords, the two tasks produce much more comparable times $(740 \mathrm{msec}$ and $683 \mathrm{msec}$, respectively), reflecting the fact that an exhaustive search is all that is required in both situations.

Although the results for unambiguous words and nonwords fit the search model neatly, the results for the homographs definitely do not. The reason for this appears to be that although $L_{1}$ is found by a search process, $L_{2}$ is not. The evidence for this is the failure of $\mathrm{f}_{2}$ to correlate with decision time for homographs, and the fact that equiprobable homographs were not classified faster than unequiprobable homographs, despite the fact that $f_{2}$ must be higher for equiprobable homographs when total frequency of occurrence is held constant. This latter result is especially surprising, since by definition, the less likely meaning of an unequiprobable homograph is less accessible than the corresponding meaning of an equiprobable homograph.

This could be explained if it was assumed that $L_{2}$ is in fact a subentry of $L_{1}$, i.e., the two meanings of a homograph are not separately stored. Or, it could be that $\mathrm{L}_{1}$ contains a cross-reference to $\mathrm{L}_{2}$. The fact that $f_{1}$ was correlated with ambiguity decision time is clearly consistent with both interpretations. The only problem with these explanations is that they fail to explain why an unambiguous word produces an exhaustive search in the ambiguity decision task, since the lack of ambiguity could be established by examining the contents of $\mathrm{L}_{1}$, thus avoiding the need to exhaustively search the remainder of the search set.

Finally, there are two incidental findings that deserve comment. First, in the lexical decision task, equiprobable homographs were not accessed faster than unambiguous words, in contrast to the findings of Rubenstein et al. (1971), who predicted such an effect on the assumption that a random search was involved. Homo. graphs, having two entries, were more likely to have one meaning sampled than words with only one meaning. The results from the previous experiment suggest that the search is not random, and that the effects reported by Rubenstein et al. (1971) may have resulted from accidental item sampling errors (see Clark, 1973, for further discussion and reanalysis of these data). Incidentally, it should be noted that the faster classification of homographs in the ambiguity decision experiment cannot be taken as support for the random sampling model, since in this task, both meanings of the homograph have to be accessed.

Second, it should be noticed that, in general, the error rates follow the trend set in the latency data, with the highest error rates being found in the slower conditions. Thus it seems unlikely that the results are due to a speed-accuracy tradeoff. One interesting result is that in the ambiguity decision task, nonwords produce a very low error rate, but precisely the same items show a very high error rate in the lexical decision task. This may reflect interesting differences between the tasks, but it should be noted that the ratio of "Yes" to "No" responses was $1: 1$ in the ambiguity decision task, compared with 4:1 in the lexical decision task (a consequence of the fact that the same materials were used in both tasks). Thus, in the lexical decision task, there would be a substantial bias towards a "Yes" response, which would elevate the error rates for nonwords. This makes the two tasks less than perfectly comparable as far as absolute decision time is concerned.

\section{EXPERIMENT II}

There are several features of the previous experiment that require further examination. First, the basic find- 
ings concerning an exhaustive search for a nonexistent entry need to be replicated, and second, further evidence relevant to the accessing of homographs is required.

Rather than use the same technique as used in the previous experiment, it was decided to develop a task which simulated more accurately the kinds of processing that normal reading involves. In normal retrieval situations, the reader is never called upon to decide how many meanings a word may have, as he is in the ambiguity decision task. Although in normal sentence processing there is evidence that the reader must find all available entries for a word (e.g., Lackner \& Garrett, 1973), he is never required to report how many entries he finds.

The technique used in this experiment focuses on the syntactic functions that a word can have, rather than meaning per se. Instead of being presented with a single word, the subject is given two words, the first always being either the word the or to. When the test item is preceded by the, subjects are required to decide whether the item can be used as a noun, and when it is preceded by to, they must decide whether it can be used as a verb. We shall refer to this type of decision as a syntactic function decision.

By selecting appropriate types of items, the essential features of the conditions used in Experiment $I$ can be duplicated without asking the subject to decide whether the item is ambiguous or not. Consider the syntactically ambiguous item house. This word is used more frequently as a noun than as a verb, and words of this type will be referred to as $N / V$ words. On the assumption that these two uses have quite separate entries, with the noun use (the more frequent) being specified in $\mathrm{L}_{1}$, and the verb use in $L_{2}$, then we can estimate the time required to access $\mathrm{L}_{1}$ by presenting the item the house (which requires a search for a noun function, i.e., a "noun search"), and the time required to access $L_{2}$ by presenting to house (which we will refer to as "verb search").

Thus, performing a verb search on an N/V word is equivalent to ambiguity decision on a homograph (since $\mathrm{L}_{2}$ must be accessed in both cases), while performing a noun search on the same word is equivalent to lexical decision on a homograph (since $\mathrm{L}_{1}$ is accessed in both cases). The situation is completely reversed for $\mathrm{V} / \mathrm{N}$ words, that is, words which are used more often as verbs than as nouns.

The analysis of the syntactic function task from the point of view of the search model is given in Figure 2. The design includes five different classes of words: $\mathrm{V} / \mathrm{N}$, $\mathrm{N} / \mathrm{V}$, unambiguous nouns, unambiguous verbs, and ambiguous nouns (both uses being nouns). Each of the first four classes was subdivided into a high and a low frequency group according to Kucera-Francis frequency. In each case, the correct answer is "Yes," if the word can be used as the part of speech specified by the function word. The remaining condition included a sample of legal nonwords, the correct answer being "no" for both noun and verb searches. The rather
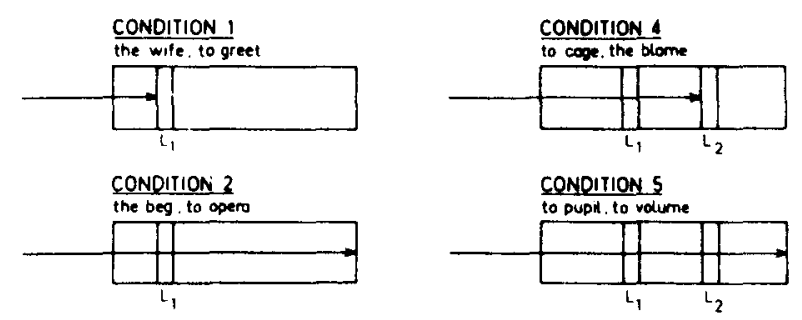

CONDITION 3
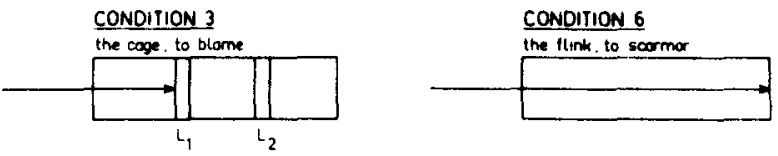

Figure 2. Schematic representation of the search process for typical items in the syntactic function task.

complex set of predictions generated by the search model are summarized as follows.

(1) Exhaustive search for nonexistent entries. When a verb search is performed on an unambiguous noun (e.g., to opera), or a noun search is performed on an unambig uous verb (the beg), as in Condition 2 , then an exhaustive search for the nonexistent entry is required. Hence there should be no effect of frequency in this condition. However, when the target of the search is in fact $\mathrm{L}_{1}$, as it is in Condition 1 (the opera, to beg), then exactly the same words as used in Condition 2 should produce a normal frequency effect (this condition being essentially the same as lexical decision). Further, decision latencies in both Condition 2 and Condition 6 (nonwords) should be longer than in Condition 1.

(2) Interruption effects. It was found in the previous experiment that when the search is required to pass $\mathrm{L}_{1}$, there was a substantial increase in decision time, presumably due to the fact that the search was interrup. ted when $L_{1}$ was encountered. This hypothesis is tested in the present experiment by a comparison of Condittion 2 (to opera, the beg), with Condition 6, where either noun or verb searches are required for nonwords (the flink, to scarmor). Decision times should be faster in the latter case, since there is no interruption to the search process A stronger test of this hypothesis is provided by comparing Condition 2 with Condition 5 , which involves a verb search on ambiguous nouns, where both meanings are nouns (to pupil, to volume). In the latter case, the search is interrupted twice, and hence Condition 5 should be slower than Condition 2 .

(3) Accessing of $\mathbf{L}_{2}$. In the previous experiment, the fact that ambiguity decision times were slower than lexical decision times was taken as evidence that $\mathrm{L}_{2}$ took longer to access than $L_{1}$. A more direct test of this hypothesis is provided in the present experiment by a comparison of Condition 3 , in which $L_{1}$ is accessed (a verb search on $\mathrm{V} / \mathrm{N}$ words, e.g., to blame, or a noun search on N/V words, e.g., the club), with Condition 4, in which $\mathrm{L}_{2}$ is accessed (a noun search on $\mathrm{V} / \mathrm{N}$ words, e.g., the blame, or a verb search on $\mathrm{N} / \mathrm{V}$ words, e.g., to club). If $\mathrm{L}_{2}$ takes longer to access than $\mathrm{L}_{1}$, then Condition 4 should take longer than Condition 3 . 
Further, decision times in Condition 3 , where $L_{1}$ is accessed, should be correlated with rated estimates of $\mathrm{f}_{1}$, and decision times in Condition 4 , where $L_{2}$ is accessed, should be correlated with rated estimates of $f_{2}$. However, if the findings of the previous experiment are correct, then both sets of decision times will in fact be correlated with $f_{1}$, with $f_{2}$ again being uncorrelated with access time for $L_{2}$ (Condition 4 ).

In evaluating the results for the homographs, an important difference between the two experiments should be noted. In Experiment I, the homographs were all unsystematic, whereas in the present many were in fact systematic. This stems from the fact that most homographs which can be used both as nouns and verbs are systematic homographs. The theoretical significance of this fact is that there are some grounds for arguing that $\mathrm{L}_{2}$ may in fact be a subentry of $L_{1}$ when the meanings are closely related. This may affect the predictions for conditions involving accessing of $\mathrm{L}_{2}$, but should not affect any other comparisons.

\section{Method}

Selection of items. The design of the experiment required four groups of words (20 in each group) matched for KuceraFrancis frequency and length, each group consisting of 10 relatively high frequency words (above 18 ) and 10 low frequency words (below 18). The four groups were: N/V homographs, $\mathrm{V} / \mathrm{N}$ homographs, unambiguous nouns, and unambiguous verbs. The classification of homographs as $\mathrm{N} / \mathrm{V}$ (the noun usage being more frequent than the verb usage) and $\mathrm{V} / \mathrm{N}$ (verb more frequent than noun) was made on the basis of ratings of the separate frequencies as in the preceding experiment (the number of taters was 11). Ideally, there should have been only one meaning of each homograph as a noun, or as a verb, but this was difficult to achieve in practice. For example, punch has two verb meanings, if punching people is considered to be different from punching IBM cards. The numbers of words having dual verb uses was low, and roughly equal in the two homograph groups ( 3 in the $\mathrm{V} / \mathrm{N}$ group, and 2 in the $\mathrm{N} / \mathrm{V}$ group). Dual noun uses were more common, with 5 in the $\mathrm{V} / \mathrm{N}$ group and 10 in the $N / V$ group. The instructions to the raters did not distinguish among these meanings, however. The raters were asked to rate only how often a word was used as a noun or as a verb.

Half of these 80 words were presented to one group of subjects with the function word "to" (i.e., requiring a verb search) and half with "the" (requiring a noun search), with the second group of subjects receiving the reverse assignment. The correct answer for the 40 homographs was "Yes" no matter what type of search was required. For the unambiguous words, 20 required a "Yes" response (nouns presented with "the" and verbs presented with "to"), and 20 required a "No" response (nouns with "to" and verbs with "the").

A further 60 items which required a "No" response were included for both groups of subjects. These consisted of 20 legal nonwords, half presented with "the," half with "to" for one group, with the reverse presentation for the second group; 20 ambiguous nouns which could not be used as verbs (e.g., pupil), all presented with "to" for both groups (these were not matched in frequency with the first four classes of words since an exhaustive search would be involved; the mean frequency for this group was 71.9 compared with a range of 47.9 to 52.8 for the first four groups); finally, an unselected set of 20 verbs was presented with "the" as filler items. The data from these words were not used. The complete set of items is listed in the appendix.

Procedure. Each item was typed on a card, with either the word "the" or "to" preceding it, with a normal single space between the words. The items were presented by means of a two-field tachistoscope. Subjects were instructed to respond by pressing a button labeled "Yes" if an item preceded by "the" could be used as a noun, or if an item preceded by "to" could be used as a verb (it was stressed that "to" was not to be taken as a preposition, and any items which might have caused confusion, e.g., to town, were avoided). Otherwise, the response was "No." Half the subjects held the "Yes" button in the preferred hand, half in the nonpreferred hand. The subjects were instructed to respond as quickly as possible, but to avoid making errors. Each stimulus item was displayed for $600 \mathrm{msec}$.

The items were presented in a semirandom order so that practice effects would be evenly distributed across all conditions. Except for the ambiguous nouns which were presented with "to" for all subjects, and the unambiguous verb filler items which were presented with "the," half the items in each condition were presented with "the" to half the subjects, the remainder being presented with "to," with the reverse assignment being used for the remaining subjects.

Subjects. A total of 20 volunteer undergraduates served as subjects, and were paid for their participation in the experiment.

Table 3

Mean Reaction Time (Milliseconds) and Percentage Error Rate as a Function of Item Type and Kucera-Francis Frequency for the Syntactic Function Task: Experiment II

\begin{tabular}{|c|c|c|c|c|c|c|c|c|}
\hline \multirow[b]{2}{*}{ Condition } & \multirow[b]{2}{*}{ Item } & \multirow[b]{2}{*}{$\begin{array}{c}\text { Search } \\
\text { Type }\end{array}$} & \multicolumn{3}{|c|}{ High Frequency } & \multicolumn{3}{|c|}{ Low Frequency } \\
\hline & & & RT & SE & $\begin{array}{c}\% \\
\text { Error }\end{array}$ & RT & SE & $\begin{array}{c}\% \\
\text { Error }\end{array}$ \\
\hline 1 & $\begin{array}{l}\text { Unambiguous Noun } \\
\text { Unambiguous Verb }\end{array}$ & $\begin{array}{l}\text { Noun } \\
\text { Verb }\end{array}$ & 695 & 20 & 7 & 770 & 24 & 11 \\
\hline 2 & $\begin{array}{l}\text { Unambiguous Noun } \\
\text { Unambiguous Verb }\end{array}$ & $\begin{array}{l}\text { Verb } \\
\text { Noun }\end{array}$ & 869 & 24 & 19 & 889 & 28 & 15 \\
\hline 3 & $\begin{array}{l}\text { N/V Homograph } \\
\text { V/N Homograph }\end{array}$ & $\begin{array}{l}\text { Noun } \\
\text { Verb }\end{array}$ & 680 & 20 & 8 & 709 & 19 & 3 \\
\hline 4 & $\begin{array}{l}\text { N/V Homograph } \\
\text { V/N Homograph }\end{array}$ & $\begin{array}{l}\text { Verb } \\
\text { Noun }\end{array}$ & 779 & 23 & 15 & 784 & 23 & 24 \\
\hline 5 & Ambiguous Noun & Verb & 957 & 32 & 28 & 952 & 32 & 24 \\
\hline 6 & $\begin{array}{l}\text { Legal Nonword } \\
\text { Legal Nonword }\end{array}$ & $\begin{array}{l}\text { Noun } \\
\text { Verb }\end{array}$ & 810 & 28 & 5 & & & \\
\hline
\end{tabular}

Note. The SE estimates are based on between-subject variation only. 


\section{Results and Discussion}

The method for calculating subject and item means was the same as in Experiment $\mathrm{I}$. The means for each condition are shown in Table 3 , and for purposes of clarity, performance has been averaged over the two types of search involved in each condition.

Taking the predictions in order, it can be seen that the predictions derived from the assumption of exhaustive search are confirmed. In Condition 2 , where the target of the search is a nonexistent entry (a noun search on unambiguous words, or a verb search on unambiguous nouns), there is no significant effect of Kucera-Francis frequency on decision time [min $F^{\prime}$ $(1 / 57)=0.52, p>.05]$, although there is a small effect $(20 \mathrm{msec})$ in the direction expected for frequency effects. However, in Condition 1, where the same items are involved in a self-terminating search (noun search on nouns, verb search on verbs), there is a much stronger effect of frequency $(75 \mathrm{msec})$, which is significant [min $\left.F^{\prime}(1 / 57)=10.77, p<.01\right]$ (no other frequency effects were significant). Further, the terminating search (Condition 1) takes only $733 \mathrm{msec}$, compared with $879 \mathrm{msec}$ for the exhaustive search required in Condition 2 [min $\left.F^{\prime}(1 / 52)=44.44, p<.001\right]$, and $810 \mathrm{msec}$ for the exhaustive search required in Condition 6 (nonwords) [ $\left.\min \mathrm{F}^{\prime}(1 / 72)=8.58, \mathrm{p}<.01\right]$.

There is one further aspect of the results that is consistent with the exhaustive search assumption. In Condition 2 , the time taken to search from $\mathrm{L}_{1}$ (the inappropriate entry) to the end of the search subset should be negatively correlated with the time taken to search from the beginning of the subset to $L_{1}$. That is, the closer $L_{1}$ is to the beginning of the set, the longer it should take to search from $L_{1}$ to the end of the set. Thus decision time for an item in Condition 1 (time taken to reach $\mathrm{L}_{1}$ ) should correlate negatively with the difference between the decision times for the same item in Conditions 1 and 2 (time taken to search from $\mathrm{L}_{1}$ to the end). The obtained correlation was in the correct direction, and was significant $[\mathrm{r}(38)=-0.64, \mathrm{p}<.001]$.

The predictions derived from the assumption of interruption effects when the search is required to pass an entry for a word are also confirmed. This is shown by the fact that an exhaustive search is faster when the item has no lexical entries at all (Condition 6) compared with the condition in which one entry must be bypassed $\left(\right.$ Condition 2) $\left[\min F^{\prime}(1 / 89)=8.17, p<.01\right]$. The duration of this interruption is $69 \mathrm{msec}$. Further support for this hypothesis is given by the fact that an exhaustive verb search on ambiguous nouns (Condition 5), where the search is interrupted twice, takes longer than an exhaustive search that is interrupted only once (Condition 2) $\left[\min F^{\prime}(1 / 64)=8.31, p<.01\right]$. The estimate of the interruption time here, $76 \mathrm{msec}$, agrees quite closely with the previous estimate, but both estimates are considerably shorter than the interruption effect observed in Experiment I ( $350 \mathrm{msec}$ ).
The results in Condition 5 are also relevant to the prediction that Kucera-Francis frequency would be unrelated to performance when an exhaustive search is involved, since in this condition, the low frequency items were actually slightly faster than the high frequency items.

Finally, the results for Conditions 3 and 4 strongly confirm the expectation that $\mathrm{L}_{2}$ would take longer to access than $L_{1}$. Access time for $L_{1}$ in Condition 3 was $695 \mathrm{msec}$, compared to $782 \mathrm{msec}$ in Condition 4 [min $\mathrm{F}^{\prime}$ $(1 / 58)=17.36, p<.01]$. However, some of this difference must be due to the interruption effect when $L_{1}$ is bypassed in Condition 4. Assuming this effect to be approximately $70 \mathrm{msec}$ (as shown above), there is only about $17 \mathrm{msec}$ left unaccounted for, which could be interpreted as the time taken to get from $L_{1}$ to $L_{2}$.

However, although $\mathrm{L}_{2}$ takes longer to access than $\mathrm{L}_{1}$, the access time for $L_{2}$ is not predictable from frequency, as shown by the insignificant correlation between rated estimates of $f_{2}$ and decision time in Condition 4 $[r(38)=-0.16, p>.05]$. Exactly the same result was found in Experiment I. On the other hand, $f_{1}$ proved to be a reasonable predictor of access time for $L_{1}$ (as in Experiment I) as shown by the significant correlation between rated estimates of $f_{1}$ and decision time in Condition $3[\mathrm{r}(38)=-0.49, \mathrm{p}<.01]$. However, contrary to the results of the previous experiment, $\mathrm{f}_{1}$ did not correlate with access times for $L_{2},[r(38)=-0.15$, $p>.05]$. Thus access time for $L_{1}$ depends on $f_{1}$, but access time for $L_{2}$ depends on neither $f_{1}$ nor $f_{2}$. This cannot be attributed to any lack of reliability in the ratings of $f_{2}$, since the split-half reliability was 0.82 , compared with 0.74 for the ratings of $f_{1}$.

Since the difference between access times for $L_{1}$ and $\mathrm{L}_{2}$ is so close to the estimate of the interruption time involved in bypassing $L_{1}$, it might be suggested that $L_{2}$ is effectively adjacent to $L_{1}$. This is indistinguishable from the earlier suggestion that $L_{2}$ might be a subentry of $L_{1}$. However, two facts argue against this interpretation. Access time for $\mathbf{L}_{2}$ would have to correlate with $f_{1}$, which, as we have already seen, was not the case in this experiment. Also, access time for $L_{2}$ should be highly positively correlated across items with access time for $\mathrm{L}_{1}$. However, the obtained correlation between decision times in Conditions 3 and 4 over the same set of items was negative and nonsignificant, $[\mathrm{r}(38)=-0.11$, $p>05]$. Thus, the accessing of $L_{1}$ and $L_{2}$ are quite independent events.

These conclusions were not altered when the analysis was restricted to just the systematic homographs; for these items, the correlation between Conditions 3 and 4 was still negative $[\mathrm{r}(16)=-0.48, \mathrm{p}<.05]$.

There are two additional findings that should be mentioned. First, it will be noticed that $L_{1}$ is accessed faster when the word is a homograph (Condition 3) compared with unambiguous words (Condition $1,733 \mathrm{msec}$ ). This difference was significant $\left[\mathrm{min} \mathrm{F}^{\prime}(1 / 56)=5.39\right.$, 
$\mathrm{p}<.05]$. For several reasons, this is a puzzling result, since (a) the same result was not obtained in the corresponding conditions of Experiment I (lexical decision time for equiprobable homographs and unambiguous words), (b) it goes against frequency effects $\left(f_{1}\right.$ will be higher for unambiguous words), and (c) although this is the effect predicted by the random search model of Rubenstein et al. (1971), there is no theoretical basis for expecting such an effect when the target of the search is specified as one of the two entries, instead of either, as in a lexical decision experiment.

The second incidental finding of interest is that there was no difference between verb searches and noun searches. This is best illustrated in Condition 6 (nonwords) where the time required for noun searches $(820 \mathrm{msec})$ did not differ significantly from the time required for verb searches $(800 \mathrm{msec})$ [min $F^{\prime}(1 / 33)$ $=0.31, p>05]$. Similar comparisons in other conditions also failed to show any significant differences.

\section{GENERAL DISCUSSION}

While there are several aspects of the data that do not readily fit any model, there are a number of findings which provide support for the central assumptions of the search model. The major conclusions to be drawn from these experiments are as follows.

(1) When a word has only one lexical entry, and the target of the search is specified in that entry (e.g., lexical decision in Experiment $I$, and either noun searches on nouns, or verb searches on verbs, in Experiment II), then decision time is controlled by the Kucera-Francis frequency of the word. But when the target is not found in that entry, decision time is increased substantially, and frequency no longer determines decision time (e.g., ambiguity decision on unambiguous words in Experiment $I$, and either a verb search on nouns, or a noun search on verbs, in Experiment II). Both results confirm the assumption of exhaustive search. In addition, the fact that the extra time required in Condition 4 compared with Condition 3 is negatively correlated with the time required to access $L_{2}$ is strong support for the notion of an exhaustive search.

(2) Both meanings of a homograph are not simultaneously available, but are accessed sequentially. The order in which the meanings become available is predictable from their relative (rated) frequencies of occurrence. That is, the most frequently used meaning is accessed faster than other meanings. The evidence for this conclusion is the fact that ambiguity decision times are substantially longer than lexical decision times (Experiment I), and the fact that a verb search is faster than a noun search for $\mathrm{V} / \mathrm{N}$ homographs, but the reverse is true for N/V homographs (Experiment II).

(3) When the task requires the search to proceed past one lexical entry, the search process appears to be interrupted briefly. The evidence for this interruption is the fact that ambiguity decisions for nonwords are faster than for unambiguous words (Experiment I), and the fact that in Experiment II, both noun and verb searches on nonwords (Condition 6) are faster than verb searches on unambiguous nouns and noun searches on unambiguous verbs (Condition 2). Further support for this conclusion is provided in Experiment II by the fact that the search for a nonexistent verb entry with ambig. uous nouns (Condition 5) is slower than the search for a nonexistent entry when the item is unambiguous (Condition 2). As noted earlier, the two experiments disagree in their estimates of the magnitude of the interruption effect. This probably reflects differences between the tasks. In the first experiment, a full semantic specification would need to be extracted from $L_{1}$ in order to compare this with the semantic specification in $\mathrm{L}_{2}$, thus ensuring that the second meaning is different from the first. This operation may take longer than merely determining whether the feature + Noun or $+V e r b$ is present in the entry, which is all that is required in the second experiment.

(4) The search model completely fails to explain the processes responsible for accessing $\mathrm{L}_{2}$. This is shown by the fact that in both experiments, the additional time to access $L_{2}$ is not predictable from frequency data. However, it seems likely that any theory of lexical access would experience difficulty here, since there are two features of the results which defy interpretation. First, in Experiment, I, unequiprobable homographs were judged to be ambiguous in the same time as equiprobable homographs. Second, in Experiment II, access times for $L_{1}$ and $L_{2}$ were not positively correlated either for systematic or unsystematic homographs.

The first of these findings could be explained by a search model which assumed either that $L_{2}$ is a subentry of $\mathrm{L}_{1}$, or that $\mathrm{L}_{1}$ contains a cross-reference to $\mathrm{L}_{2}$ (these alternatives being essentially equivalent). However, the second finding could not readily be explained in this way, which of course is also the case for a number of findings reported in this paper (e.g., all the results predicted from the assumption of exhaustive search).

In general terms, it appears that the search model correctly predicts many features of the results when either $L_{1}$ is being accessed, or when the target is a nonexistent entry. However, whenever the target is contained within $L_{2}$, the search model correctly predicts only that access time will be longer than when the target is contained within $\mathrm{L}_{1}$. All other predictions fail.

This would normally count as sufficient grounds for rejecting the search model, but in this case it seems inappropriate to do so, since there appears to be no alternative model which performs any better. The most obvious alternative is a content-addressable memory system with direct access to a single entry in which all meanings are listed. This model could easily account for differences in the access times for the different meanings of a homograph (the most common meaning is listed first), and even interruption effects (the contents of the entry have to be searched in order to determine that the 
target is not present). However, it connot account for either the presence of a frequency effect for lexical decisions, or the absence of such an effect for ambiguity decisions. Similarly, in Experiment II, it cannot explain why frequency controls decision time in Condition 1 , but not in Condition 2. Of course, it also cannot explain the fact that the accessing of the two meanings of a homograph appear to be quite independent events.

Finally, a brief comment on the notion of search. It is often argued that there is little point in exploring a search model of lexical access, since the scanning rates that would have to be involved are impossibly high. This criticism entirely prejudges the issue. For one thing, we do not know the size of the search set (it need not be the entire lexicon), and hence we cannot specify the required scanning rate. But even if the search set is in fact the total lexicon, we still do not really know how fast the search could be carried out. For example, consider the possibility that the lexicon is subdivided into a number of subsets, which are searched in parallel. Within a single subset, the search rate might be quite slow, but when this rate is multiplied by the number of searches that can be carried out in parallel, the effective search rate may be very high indeed.

\section{REFERENCES}

Clark, H. H. The language-as-fixed-effect fallacy: A critique of language statistics in psychological research. Journal of Verbal Learning and Verbal Behavior, 1973, 12, 335-359.

Forster, K. I., \& Chambers, S. M. Lexical access and naming time. Journal of Verbal Learning and Verbal Behavior, 1973. $12,627-635$

Lackner, J. R., \& Garrett, M. F. Resolving ambiguity: Effects of biasing context in the unattended ear. Cognition, 1973, 1 , 359-372.

Kucera, H., \& Francis, W. N. Computational analysis of presentday American English. Providence, R. I.: Brown University Press, 1967.

Rubenstein, H., Garfield, L., \& Millikan, J. A. Homographic entries in the internal lexicon. Journal of Verbal Learning and Verbal Behavior, 1970, 9, 487-494.

Rubenstein, H., Lewis, S. S., \& Rubenstein, M. A. Homographic entries in the internal lexicon: Effects of systematicity and relative frequency of meaning. Journal of Verbal Learning and Verbal Behavior, 1971, 10,57-62.

Snodgrass, J. G., \& Jarvella, R. J. Some linguistic determinants of word classification times. Psychonomic Science, 1972, 27, 220-222.

Stanners, R. F., \& Forbach, G. B. Analysis of letter strings in word recognition. Journal of Experimental Psychology, $1973,98,31-35$.

(Received for publication January 27, 1975 .

Revision received April 25, 1975.)

\section{APPENDIX}

\section{ITEMS USED IN EXPERIMENT I}

Equiprobable homographs:

yard, coach, park, patient, stick, order, stern, second, temple, express, batter, scrub, yarn, clog, resort, hamper, bark, crank, poach, poker.

\section{Unequiprobable homographs:}

mate, habit, note, bridge, pride, sound, pupil, interest, count, sentence, jumper, steer, pine, fray, prompt, cordial, boil, hedge, cuff, stole.

\section{Unambiguous words:}

fled, tooth, hotel, kitchen, porch, child, glory, problem, enjoy, guidance, negate, filly, woke, fern, ghost, sensual, ripe, shrub, pomp, tiger.

\section{Nonwords:}

dister, glant, pote, tufk, flink, doskeer, saft, quarp, plam, fegol, fewt, strig, blent, scarmor, herve, blask, sholk, treaper, driky, crointer.

\section{ITEMS USED IN EXPERIMENT II}

\section{V/N homographs:}

show, care, pass, ride, win, drop, shift, blame, hope, slip, chase, leap, steer, boil, hunt, scrub, punch, bustle, blunt, graze.

\section{N/V homographs:}

book, club, bridge, snow, box, suit, iron, bomb, season, mate, graph, drum, mint, coin, cage, tunnel, crane, sock, feast, hedge.

\section{Unambiguous words - nouns:}

wife, food, event, bible, song, desk, atom, opera, hotel, tent, chaos, monk, wheat, moss, pork, gland, axle, trout, cobra, friar.

Verbs:

tell, bring, learn, avoid, seek, deny, teach, argue, speak, cope, quit, bake, greet, beg, unite, notify, vanish, coax, allege, writhe.

\section{Nonwords:}

dister, glant, pote, tufk, flink, doskeer, saft, quarp, plam, fegol, sholke, strig, trep, drik, blent, scarmor, cron, herve, fewt, blask.

\section{Ambiguous nouns used in Condition 5:}

feet, bit, volume, vice, country, league, temple, party, speech, flight, racket, jumper, horn, pupil, deed, organ, nerve, cape, mole, stole. 